Article

\title{
Experimental Study on High-Performers Quaternary Copolymer Based on Host-Guest Effect
}

\author{
Tao Xu (D), Jincheng Mao*(D), Yang Zhang *, Xiaojiang Yang, Chong Lin, Anqi Du, Heng Zhang, Quan Zhang \\ and Jinhua Mao *
}

Citation: Xu, T.; Mao, J.; Zhang, Y.; Yang, X.; Lin, C.; Du, A.; Zhang, H.; Zhang, Q.; Mao, J. Experimental Study on High-Performers Quaternary Copolymer Based on Host-Guest Effect. Polymers 2021, 13 , 2972. https://doi.org/10.3390/ polym13172972

Academic Editor: Edina Rusen

Received: 29 May 2021

Accepted: 27 August 2021

Published: 1 September 2021

Publisher's Note: MDPI stays neutral with regard to jurisdictional claims in published maps and institutional affiliations.

Copyright: (c) 2021 by the authors. Licensee MDPI, Basel, Switzerland. This article is an open access article distributed under the terms and conditions of the Creative Commons Attribution (CC BY) license (https:// creativecommons.org/licenses/by/ $4.0 /)$
State Key Laboratory of Oil and Gas Reservoir Geology and Exploitation, Southwest Petroleum University, Chengdu 610500, China; 15827742134@163.com (T.X.); xjyang@swpu.edu.cn (X.Y.); 201999010016@swpu.edu.cn (C.L.); 13880147377@163.com (A.D.); 201811000155@stu.swpu.edu.cn (H.Z.); zhangsanfengdbsy@163.com (Q.Z.)

* Correspondence: jcmao@swpu.edu.cn (J.M.); 201521000202@stu.swpu.edu.cn or yangzhang10234@163.com (Y.Z.); 201921000706@stu.swpu.edu.cn or 18328085244@163.com (J.M.); Tel.: +86-28-8303-3546 (J.M. \& Y.Z. \& J.M.)

\begin{abstract}
A quaternary polymer (HGP) was prepared by the free-radical polymerization of acrylamide, acrylic acid, maleic anhydride functionalized $\beta$-cyclodextrin (MAH- $\beta$-CD), and N-(3methacrylamidopropyl)-N, N-dimethylnaphthalen-1-aminium chloride (NAP). It was found that host-guest behavior occurred most effectively at a molar rate of NAP and CD with 1:1, which exhibited better solubility than hydrophobically associative polymer. Moreover, the as-prepared polymer has superior salt tolerance, shear resistance, and viscoelasticity due to host-guest strategy. More importantly, the HGP solution simulates the distribution of formation water in the Bohai SZ1-1 oilfield has good rheological properties at $120^{\circ} \mathrm{C}$. All results show that the proposed polymer could be a competitive candidate in oilfield applications such as fracturing fluids, displacement fluids, and drilling fluids.
\end{abstract}

Keywords: host-guest strategy; hydrophobically associating water-soluble polymers; rheological behaviors; salt tolerance; $\beta$-cyclodextrin

\section{Introduction}

Water-soluble polymers have become increasingly important in oilfield applications such as hydraulic fracturing, enhanced oil recovery, and drilling [1]. As the petroleum industry taps deeper reservoirs, there is an urgent requirement that chemicals should maintain performances in harsh reservoirs with high temperatures and salinities [2,3]. Polyacrylamide and partially hydrolyzed polyacrylamide (HPAM) are widely used in polymer flooding and hydraulic fracturing [4]. However, HPAM with poor heat resistance and salt tolerance cannot withstand the harsh reservoir [5-8].

In addition, scholars have paid increased attention in recent decades to hydrophobically associating water-soluble polymers (HAWSPs), which have good thickening and salt resistance. Hydrophobic association between the hydrophobic groups of HAWSP increases the hydrodynamic volume and increases viscosity significantly $[9,10]$. Compared with conventional water-soluble polymers, HAWSPs have poor solubility due to the presentence of hydrophobic groups, which one of the factors restricting its application in oil fields.

The host-guest effect has attracted attention in recent years because it can improve the performance of polymers. $\beta$-cyclodextrin $(\beta-C D)$ is the most used in this field [11-14]. $\beta$-CD can form supramolecular structures with guest chains by hydrogen bonding and van der Waals forces $[15,16]$. There is a network structure in such a polymer solution caused by the inclusion of the $\beta-C D$ and the guest such as phenyls, long-chain alkyls, adamantyl, and azobenzene [17-21]. Weickenmeier et al. obtained a polymer solution with an apparent supramolecular network structure attributed to the host-guest effect between $\beta$-CD polymers and hydrophobically modified polymers [22]. Wei Bing et al. grafted a 
$\beta$-CD and an adamantane ring structure on the side chain of the polymer; the superior properties make this novel polymer promising in enhancing oil recovery [23]. Zou CJ et al. prepared a new supramolecular retarded acid system by $\beta-C D$ and 2-Phosphonobutane-1, 2, 4-Tricarboxylic Acid, which can decrease the corrosion rate with formations [24]. Due to the spatial position of the host-guest molecules on the polymer chain and the difference in their molecular activation energy, the rheological behavior of the polymer solution system is significantly different. According to previous studies, grafting of $\beta$-CD groups in a HAWSP can produce host-guest interactions, improving properties such as solubility and temperature, salt, and shear resistance $[25,26]$.

Inspired by the above, a quaternary polymer (HGP) was designed by copolymerizing acrylamide (AM), acrylic acid (AA), and two kinds of monomer: $\mathrm{N}$-(3-methacrylamidopropyl)$\mathrm{N}, \mathrm{N}$-dimethylnaphthalen-1-aminium chloride (NAP) and modified maleic anhydride (MAH$\beta-C D)$. NAP and MAH- $\beta-C D$ were selected as functional monomers for the following reasons: (1) the hydrophobic cationic monomer NAP can form hydrophobic microdomains in an aqueous solution due to hydrophobic association, which significantly increases the viscoelasticity. (2) Due to the poor solubility of hydrophobically associating polymers, the introduction of cyclodextrin can speed up the dissolution of the polymer. At the same time, NAP and MAH- $\beta-C D$ have host-guest effects in the solution. It is reported that the envelope constants between cyclodextrin and naphthalene are $4.67 \times 10^{3} \mathrm{molL}^{-1}$ (Figure 1) [27]. (3) In addition, NAP and MAH- $\beta$-CD are rigid groups, which not only increase the rigidity of the backbone of the polymer but also improve the temperature resistance of the polymer.

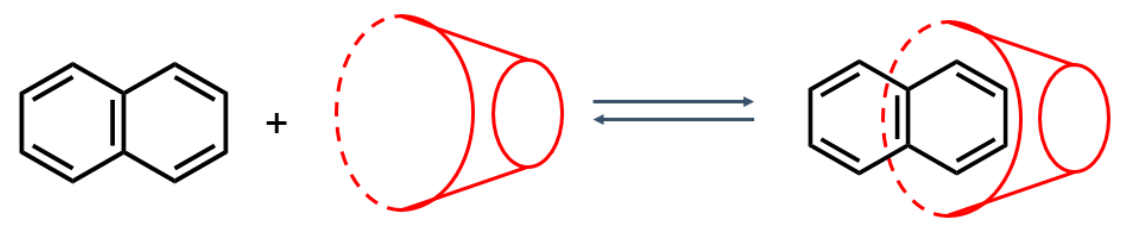

Figure 1. Cyclodextrin and naphthalene have host-guest effects.

HGP embraces good solubility, thickening performance, shear tolerance, and salt and temperature resistance due to the host-guest effect.

\section{Experimental Section}

\subsection{Materials}

$\beta$-cyclodextrin( $\beta$-CD, BR 99\%), maleic anhydride (MAH, AR 99\%), acetone (AR 98\%), chloroform Dimethylamino propyl methacrylamide (DMAPMA, AR 98\%), 1-Chloromethyl naphthalene (AR 98\%), Anhydrous methanol (AR 99.5\%) and acetonitrile (AR 99.5\%), Sodium carbonate (AR 99.5\%), Ethyl ether, Acrylamide(AM, AR 98\%), Acrylic acid (AA, AR 99.5\%), 2,2'-azobis (2-methylpropionamidine) dihydrochloride (V50, AR 98\%), sodium hydroxide, sodium chloride ( $\mathrm{NaCl}, \mathrm{AR} 99 \%$ ), potassium chloride ( $\mathrm{KCl}, \mathrm{AR} 99 \%)$, Calcium chloride anhydrous $\left(\mathrm{CaCl}_{2}, \mathrm{AR} 99 \%\right)$, and magnesium chloride $\left(\mathrm{MgCl}_{2}, \mathrm{AR} 99 \%\right)$ were purchased from Chengdu Kelong Chemical Reagents Corp. (Chengdu, China). HPAM $\left(\mathrm{Mw}=16\right.$ to $\left.18 \times 10^{6}\right)$ was purchased from the Hengju Oil Field Chemical Reagents Co, Ltd. (Beijing, China). Deionized (DI) water was obtained from a water purification system.

\subsubsection{Synthesis of MAH- $\beta-C D$}

The activity of various hydroxyl groups in cyclodextrin is different. According to nucleophilic properties, the reaction activity order of the three hydroxyl groups is C6 > C2 > C3 The steric hindrance of the 6-hydroxyl group is small, and the reaction activity is higher under acidic conditions. Therefore, the electrophilic reagent attacks the 6-hydroxyl group, and the reagent with lower reaction activity has the highest selectivity on the 6-primary hydroxyl group. In addition, through references [28,29], it was found that when the molar ratio of 1:1 for the $\mathrm{CD}$ and $\mathrm{MAH}$, the yield was higher. A mixture of $\beta-\mathrm{CD}(5.68 \mathrm{~g}, 0.005 \mathrm{~mol})$, 
MAH (4.90 g, $0.005 \mathrm{~mol})$, and anhydrous $N, N$-dimethyl formamide $(30 \mathrm{~mL})$ was stirred at $80{ }^{\circ} \mathrm{C}$ for $10 \mathrm{~h}$. Then, the reaction mixture was cooled to room temperature, and a large amount of chloroform was added to precipitate the compound. The precipitate was filtered and washed three times with a large amount of acetone. Vacuum drying the precipitate at $75^{\circ} \mathrm{C}$ for $24 \mathrm{~h}$ resulted in a $62 \%$ yield of a yellow powder (MAH- $\beta$-CD) (Scheme 1).

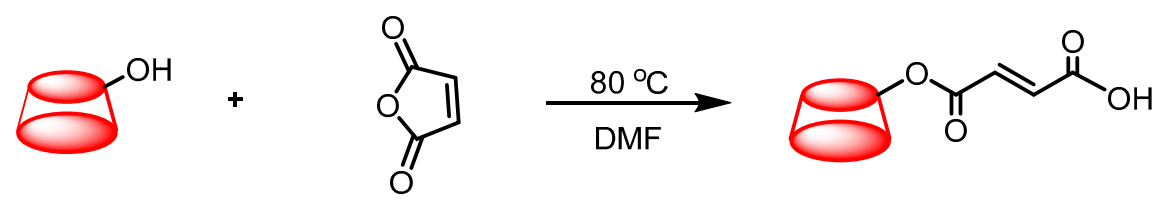

Scheme 1. Synthesis route of maleic anhydride cyclodextrin (MAH- $\beta-C D)$.

\subsubsection{Synthesis of NAP}

A mixture of (10.215 g, $0.06 \mathrm{~mol})$ DMAPMA and (10.598 g, $0.06 \mathrm{~mol})$ 1-(chloromethyl) naphthalene was added to $60 \mathrm{~mL}$ anhydrous methanol and $60 \mathrm{~mL}$ acetonitrile, and sodium carbonate $(2.11 \mathrm{~g})$ was added. The system was protected by argon and reacted at $60^{\circ} \mathrm{C}$ for $48 \mathrm{~h}$ at reflux. After the reaction, the solid was filtered, and methanol and acetonitrile were removed at $55^{\circ} \mathrm{C}$ by rotary evaporator. The concentrated substance was added to diethyl ether; there white powder was produced, named NAP (yield 91\%) (Scheme 2).<smiles>C=C(C)C(=O)NCCCN(C)[CH+]c1cccc2c(CCl)cccc12</smiles>

Scheme 2. Synthesis route of NAP.

\subsubsection{Synthesis of Copolymer}

The appropriate amounts of AM (10 g, $0.14 \mathrm{~mol}), \mathrm{AA}(2.5 \mathrm{~g}, 0.03 \mathrm{~mol}), \mathrm{MAH}-\beta-\mathrm{CD}$ $\left(0.56 \mathrm{~g}, 4.54 \times 10^{-4} \mathrm{~mol}\right)$, and NAP $\left(0.15 \mathrm{~g}, 4.54 \times 10^{-4} \mathrm{~mol}\right)$ were stirred into deionized water under a nitrogen atmosphere for $30 \mathrm{~min}$, and the total monomer concentration was maintained at $30 \mathrm{wt} . \%$. Then, the $\mathrm{pH}$ was adjusted to $7.0-8.0$ with sodium hydroxide. After complete dissolution, V50 solution was added, the content of which was $0.035 \mathrm{wt} . \%$ of the total mass of the monomer. At last, the solution was under a UV light fixture (T5 8-W $\mathrm{UVB}$ ) at $25^{\circ} \mathrm{C}$ for $8 \mathrm{~h}$ (yield $89-92 \%$ ). The product was purified three times by precipitation with ethanol dried at $25^{\circ} \mathrm{C}$. In this study, three copolymers, HGP, HP-T, and GP-T, were prepared, in which the molar ratio of MAH- $\beta-\mathrm{CD}$ to NAP in the three copolymers was 1:1, 1:0, and 0:1, respectively. The synthesis route is shown in Scheme 3.

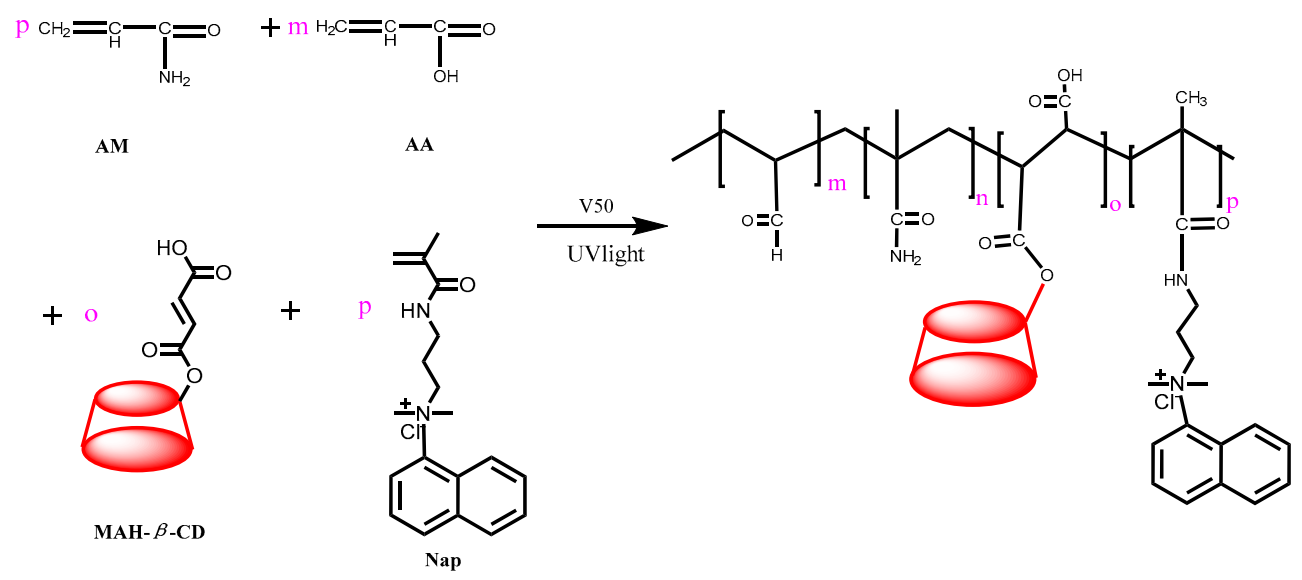

Scheme 3. Synthesis route of copolymer. 


\subsection{Characterization}

The ${ }^{1} \mathrm{H}$ NMR spectra of NAP, HGP, and MAH- $\beta$-CD were measured on a Bruker AVANCE III HD 400 spectrometer (Bruker BioSpin, Switzerland). The Fourier Transform Infrared Spectroscopy (FT-IR) of HGP was measured with Nicolet 6700 spectrophotometer.

\subsection{Effect of $\beta-C D$ and $M A H-\beta-C D$ on NAP CMC}

The influence of $\beta-\mathrm{CD}$ and $\mathrm{MAH}-\beta-\mathrm{CD}$ concentration on the surface tension of NAP was measured by KRUSS DSA30S tensiometer at $25^{\circ} \mathrm{C}$. The measurements were repeated three times independently, and the error was represented by the error strip in the figure.

\subsection{Effect on the Viscosity of the Functional Monomer}

To investigate the effect of the molar ratio of the MAH- $\beta-C D$ and NAP on the viscosity of polymer solutions, the polymer with different molar ratio of MAH- $\beta$-CD to NAP was prepared. The measurement was repeated three times independently.

\subsection{Conductivity}

In order to explore the impact of the host-guest effect on copolymers' solubility, the DDS-307 ${ }^{+}$conductivity meter (Chengdu Century Ark Technology Co., Ltd., Chengdu, China) was used to measure the conductivity of HGP, GP-T, and HP-T, and all experiments were conducted at $25{ }^{\circ} \mathrm{C}$. The measurement was repeated three times independently.

\subsection{Thickening Performance}

The viscosities of the copolymer solutions with various concentrations were measured by HAAKE RS600 rheometer (Thermo Fisher Scientific, 81 Wyman Street, Waltham, MA, USA) at $170 \mathrm{~s}^{-1}$ and $25^{\circ} \mathrm{C}$. The measurement was repeated three times independently.

\subsection{Microstructure Analysis}

The microstructure of the HGP, HP-T and GP-T solutions was observed by environmental scanning electron microscope (ESEM; Quanta 450, Hillsboro, OR, USA). All samples were frozen at $-50^{\circ} \mathrm{C}$ using liquid nitrogen, and the frozen surfaces of the samples were observed with the ESEM operating at an accelerating voltage of $20 \mathrm{kV}$.

\subsection{Viscoelasticity}

The viscoelasticity of copolymers solutions was measured by an Anton Paar rheometer (MCR302) with CP50-1-SN30644 plate fixture (diameter $=0.099 \mathrm{~mm}$ ) at $25{ }^{\circ} \mathrm{C}$. The measurement was repeated three times independently.

\subsection{Shear Tolerance}

The shear tolerances of the copolymer solutions ( $0.6 \mathrm{wt} . \%)$ were measured by a continuous shear from $7.31 \mathrm{~s}^{-1}$ to $1000 \mathrm{~s}^{-1}$ at $25{ }^{\circ} \mathrm{C}$ for $30 \mathrm{~min}$ by the HAAKE MAR III RS 600 rheometer. The shear recoveries of shear rates at $170 \mathrm{~s}^{-1}$ and $510 \mathrm{~s}^{-1}$ were measured under the same conditions. The measurement was repeated three times independently. The thermal shear of HGP, HP-T, and GP-T solutions was investigated. The temperature was raised from $30^{\circ} \mathrm{C}$ to $120^{\circ} \mathrm{C}$ over a period of $120 \mathrm{~min}$ at a constant shear rate of $170 \mathrm{~s}^{-1}$.

\subsection{Salt Tolerance}

To investigate the salt tolerance of the copolymer solutions HGP, HP-T, GP-T, and HPAM, the viscosity of polymers $(0.6 \mathrm{wt} . \%)$ in different concentrations of sodium chloride was measured. Similarly, the salt tolerance of the copolymers was investigated in calcium chloride solution and magnesium chloride solution, respectively. The viscosity was measured by the HAAKE rheometer at $170 \mathrm{~s}^{-1}$ and $25^{\circ} \mathrm{C}$. 


\section{Results and Discussion}

\subsection{Characterization}

The HGP structure was confirmed by ${ }^{1} \mathrm{H}$ NMR, as shown in Figure 2c. The proton signals at $4.70 \mathrm{ppm}$ were assigned to the solvent proton $\left(\mathrm{D}_{2} \mathrm{O}\right)$. Proton signals of $3.0 \mathrm{ppm}$ were assigned to $-\mathrm{N}^{+}-\mathrm{CH}_{3}$, and 5.56 to $6.24 \mathrm{ppm}$ were associated with the proton peak of naphthalene. A $0.88 \mathrm{ppm}$ proton signal could be assigned to the $-\mathrm{CH}_{3}$ proton in the polymer backbone. The proton signals of $1.603 \mathrm{ppm}$ and $2.143 \mathrm{ppm}$ were attributed to the $-\mathrm{CH}_{2}-\mathrm{CH}-$ in the polymer backbone. The two protons of the main chain of the MAH- $\beta-\mathrm{CD}$ were around $2.45 \mathrm{ppm}(-\mathrm{CH}-)$ and at $1.70 \mathrm{ppm}\left(-\mathrm{CH}_{2}-\right)$. The proton signal at $4.998 \mathrm{ppm}$ was associated with the $\beta-\mathrm{CD}$ glucose unit (O-CH-O). The mass signal was considered to be the glucose proton units $\mathrm{C}-\mathrm{CH}-\mathrm{OH}$ and $\mathrm{C}-\mathrm{CH}_{2}-\mathrm{OH}$ at $3.681 \mathrm{ppm}$. The $3.272 \mathrm{ppm}$ proton signal was derived from the $\mathrm{C}-\mathrm{CH}-\mathrm{O}$ of the glucose proton unit, which corresponds to Figure $2 \mathrm{a}$, b; the experimental results verified the identity of the synthesized polymer to the target.
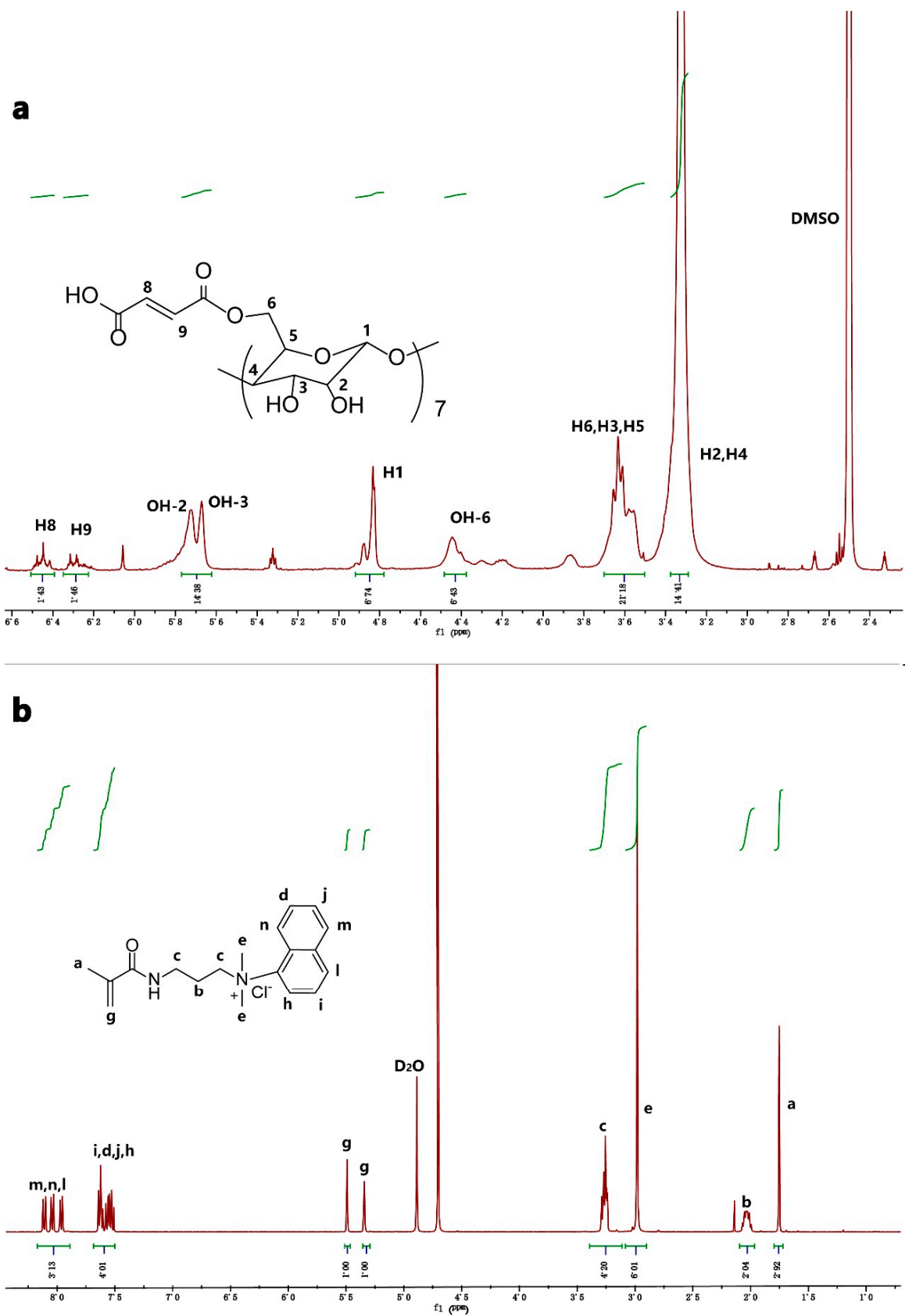

Figure 2. Cont. 


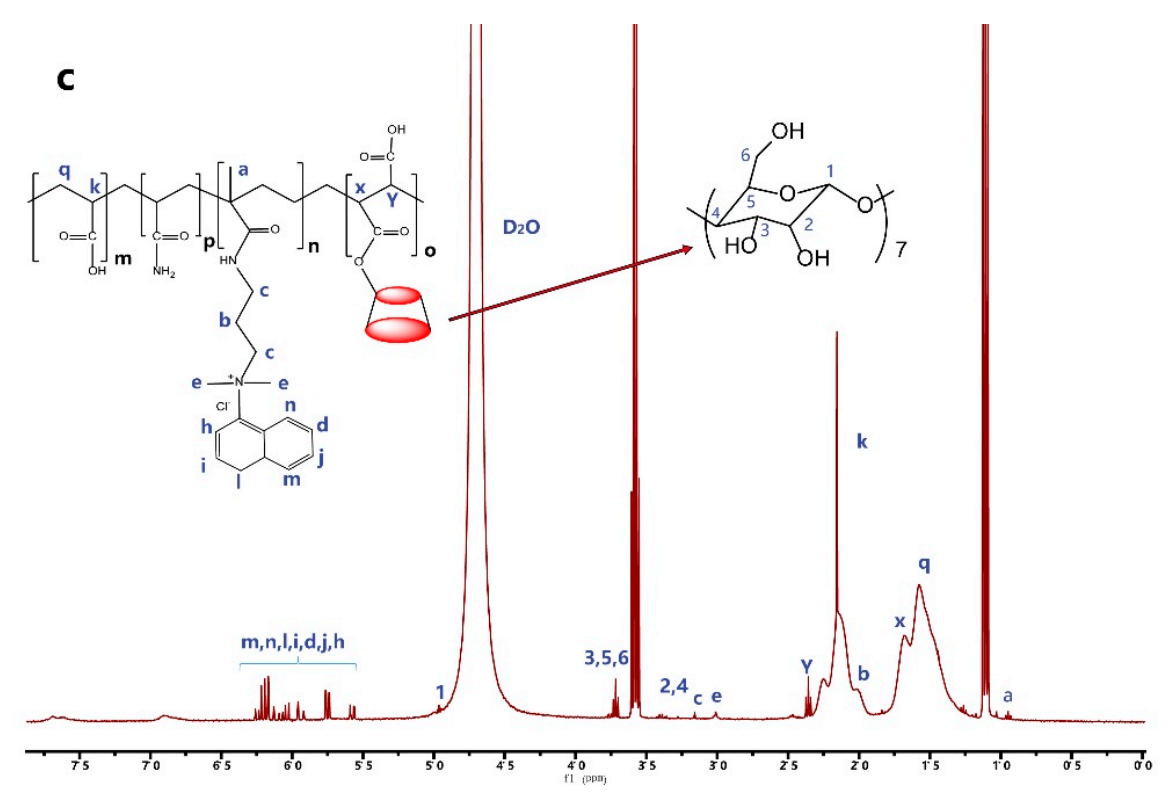

Figure 2. ${ }^{1} \mathrm{H}$ NMR spectrum: (a) MAH- $\beta-\mathrm{CD}$, DMSO; (b) NAP, $\mathrm{D}_{2} \mathrm{O}$; (c) HGP, $\mathrm{D}_{2} \mathrm{O}$.

HGP was characterized and confirmed by the FT-IR spectrum shown in Figure 3. The absorption bands at $3455 \mathrm{~cm}^{-1}$ and $1673 \mathrm{~cm}^{-1}$ were due to the stretching vibration of $\mathrm{N}-\mathrm{H}$ and $\mathrm{C}=\mathrm{O}$ in the acrylamide groups $\left(-\mathrm{CONH}_{2}\right)$. The band at $3098 \mathrm{~cm}^{-1}$ was attributed to the C-H stretching vibration of arene hydrocarbons. The band at $2927 \mathrm{~cm}^{-1}$ was due to the stretching vibration peak of $-\mathrm{CH}_{2}$. The peak at $1446 \mathrm{~cm}^{-1}$ was assigned to the stretching vibration of the arene $\mathrm{C}-\mathrm{C}$ skeleton. The $1415.4 \mathrm{~cm}^{-1}$ peak was attributed to the in-plane bending vibration peak of amide C-N and N-H. The bands observed at $1336 \mathrm{~cm}^{-1}$ was due to the vibration of $-\mathrm{CH}_{2}$. The band at $844 \mathrm{~cm}^{-1}$ was the in-plane and out-plane bending vibration of arene $\mathrm{C}-\mathrm{H}$. Furthermore, the stretching vibration of $\mathrm{C}-\mathrm{O}-\mathrm{C}$ referred to the band at $938.00 \mathrm{~cm}^{-1}$ which corresponded to the skeleton vibrations of $\beta$-CD. The FT-IR spectra confirmed that NAP and MAH- $\beta$-CD had been successfully introduced into the polymer.

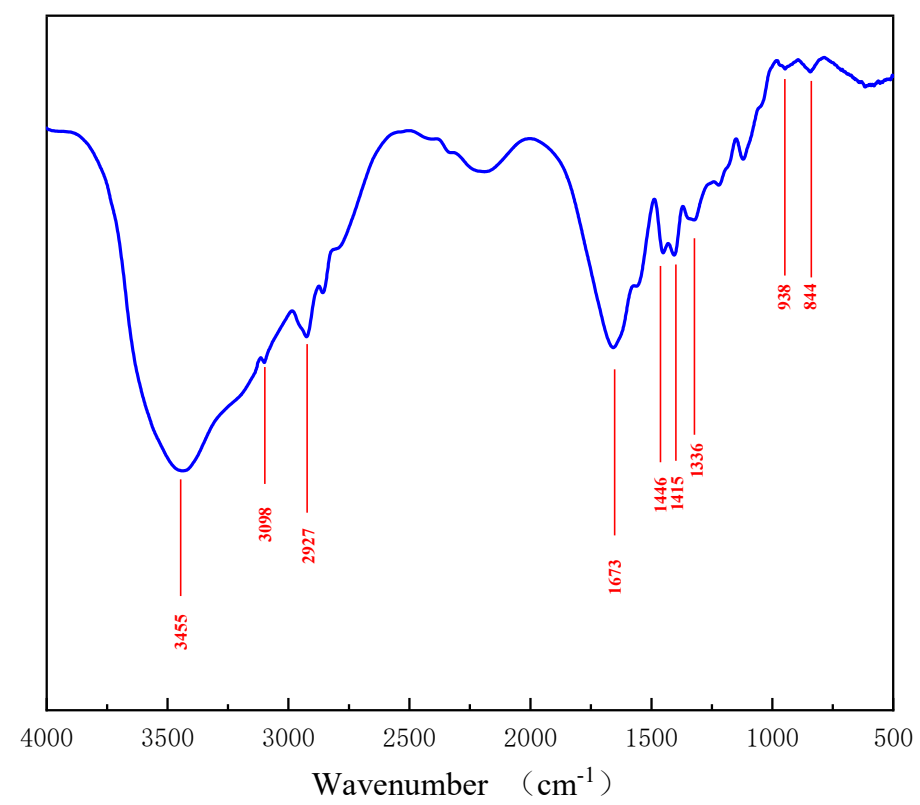

Figure 3. The FTIR spectrum of HGP. 


\subsection{Effect of $\beta-C D$ and $M A H-\beta-C D$ on NAP CMC}

The critical micelle concentration (CMC) of NAP was measured at $25^{\circ} \mathrm{C}$. As shown in Figure $4 \mathrm{a}$, with the increase in concentration, the surface tension of the NAP solution decreases continuously. When the concentration is $3.54 \times 10^{-4} \mathrm{~mol} / \mathrm{L}$, the surface tension drops to the minimum and rarely changes with the increase in concentration, indicating that the CMC of NAP is about $3.54 \times 10^{-4} \mathrm{~mol} / \mathrm{L}$. Figure $4 \mathrm{~b}$ shows the relationship between the surface tension of NAP $\left(3.54 \times 10^{-4} \mathrm{~mol} / \mathrm{L}\right)$ and the concentration of cyclodextrin $(\beta-\mathrm{CD}$ or MAH- $\beta-\mathrm{CD}$ ) at $25^{\circ} \mathrm{C}$. Clearly, with the increase in $\mathrm{CD} / \mathrm{NAP}$, the system surface tension increases continuously. When $\mathrm{CD}: \mathrm{NAP} \approx 1$, the surface tension reaches the maximum and tends to be stable. It can be seen that MAH- $\beta-C D$, like the $\beta-C D$, has a similar binding effect on hydrophobic guest NAP, and an inclusion ratio of $\mathrm{CD}: \mathrm{NAP} \approx 1$.
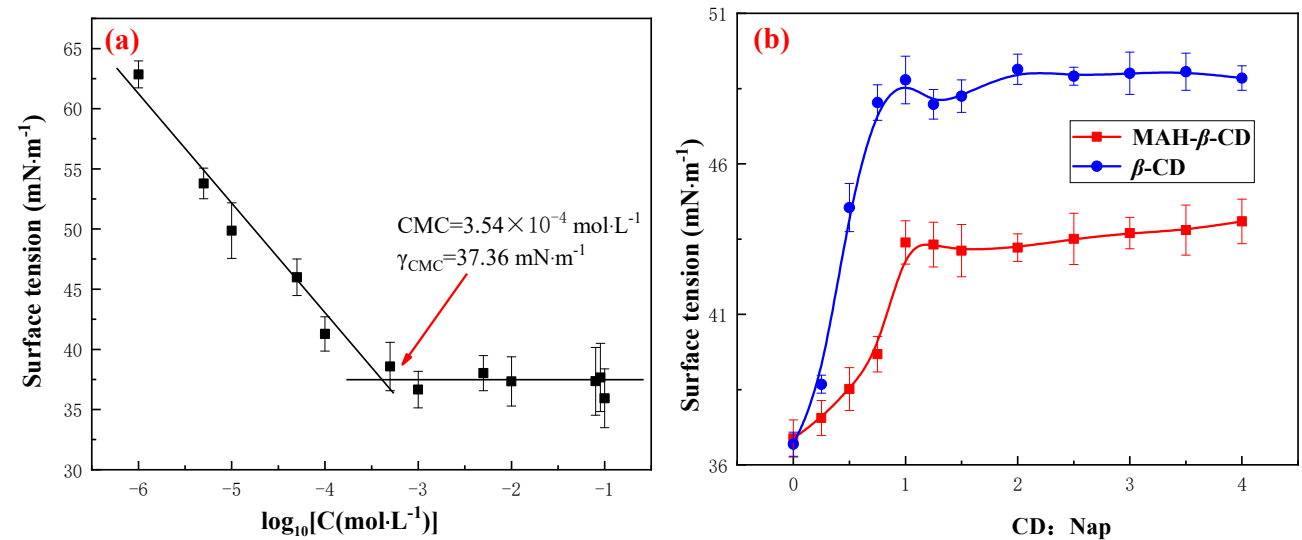

Figure 4. (a) Surface tension of NAP at $25^{\circ} \mathrm{C}$; (b) relationship between CD:NAP and NAP surface tension at $25^{\circ} \mathrm{C}$.

\subsection{Effect on the Viscosity of Host-Guest Monomer Ratio}

It is well known that monomer content has a marked effect on polymer viscosity [30]. As shown in Figure 5, with the increase in the molar ratio of the host-guest monomer, the viscosity of the solution increased first and then decreased. When the molar ratio of $\mathrm{MAH}-\beta-$ $\mathrm{CD}$ to NAP was $1: 1$, the solution viscosity reached the maximum $194 \mathrm{mPa} \cdot \mathrm{s}$, corresponding to the effect of CD on NAP CMC. The highest effective host-guest structure in the solution occurred when the molar ratio was 1:1, resulting in a significant increase in viscosity.

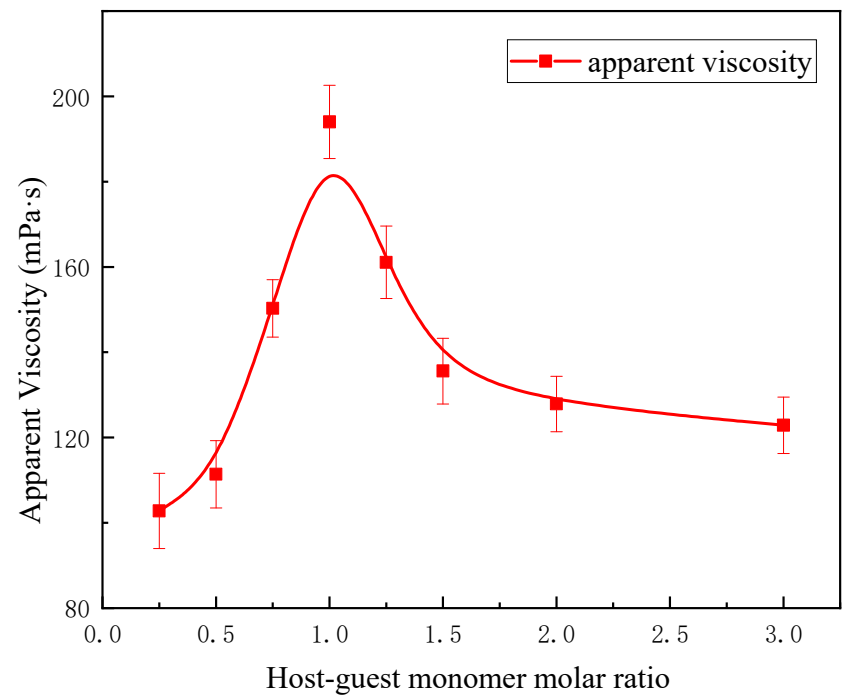

Figure 5. The $0.6 \mathrm{wt} . \% \mathrm{HGP}$ viscosity at various monomer molar ratios with a shear rate of $170 \mathrm{~s}^{-1}$ at $25{ }^{\circ} \mathrm{C}$. 


\subsection{Conductivity}

It is important for application in oilfields that polymers dissolve in water immediately. When the polymer is completely dissolved, the conductivity hardly changes over time. As shown in Figure 6, the conductivity of HGP, GP-T, and HP-T gradually stabilized over time. The conductivity of HGP and HP-T tends to stabilize quickly, at $4.2 \mathrm{~min}$ and $5.1 \mathrm{~min}$, respectively. However, the GP-T was relatively slow and did not become stable until $8.0 \mathrm{~min}$. $\beta$-CD can wrap the hydrophobic groups to form an inclusion compound due to its unique structures, including hydrophobic inner cavity and hydrophilic outer cavity. Thus, the hydrophobic association between the hydrophobic groups in the polymer was shielded, accelerating the diffusion rate of the polymer molecules to water, and reducing the dissolution time of the polymer. From this perspective, polymers using the host-guest strategy have more promising application prospects than hydrophobic associating polymers.

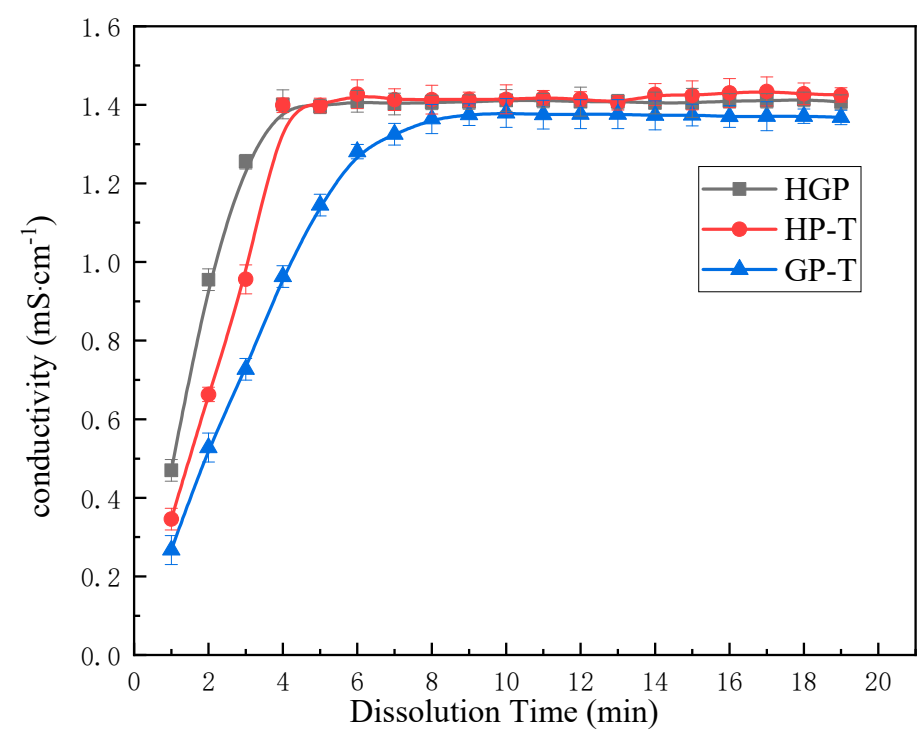

Figure 6. Conductivity changes in the dissolution process of copolymers at $25^{\circ} \mathrm{C}$.

\subsection{Thickening Performance}

The viscosity of the polymer solution increases as the concentration increases. As shown in Figure 7, the four polymers exhibited good proportional linear thickening properties. When the concentration increased from $1000 \mathrm{mg} / \mathrm{L}$ to $3500 \mathrm{mg} / \mathrm{L}$, the growth rate in viscosity of the HGP was the highest $(168 \%)$, and HP-T had the lowest liquid viscosity growth rate $(92.5 \%)$. This could be interpreted as follows: at low concentrations, the system thickening effect was not obvious, but when the concentration was more than $1000 \mathrm{mg} / \mathrm{L}$, the inclusion effect became significant, and the host-guest recognition between the $\beta$-CD and NAP on the polymer formed a cross-linked 3D network structure. In addition, the hydrophobic association also contributes to viscosity, as shown in Figure 8. As a result, the viscosity of HGP rose sharply.

\subsection{Microstructure Analysis}

ESEM was used to investigate the reasons for the increase in polymer viscosity. In Figure 9, microcosmic network structures in HGP are much denser than those of GP-T and HP-T. As shown in Figure 9a, there is a noticeable multilayer 3D structure containing pores with different sizes in the HGP solution as a result of the host-guest effect, which could not only support the polymer chain but also encapsulate a lot of water. In other words, the host-guest effect can increase the apparent viscosity and deformation resistance. 


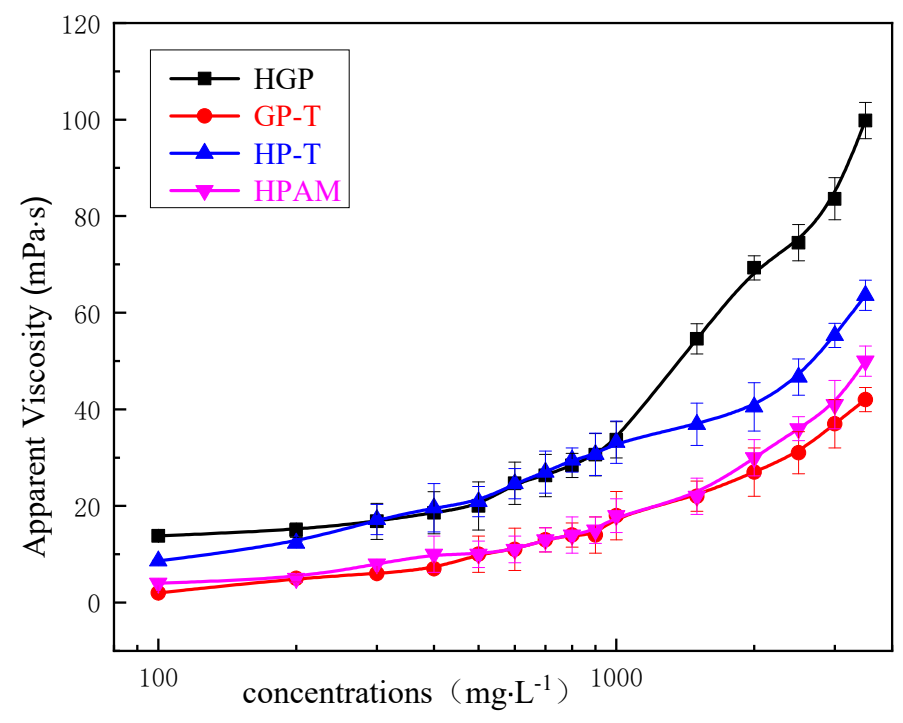

Figure 7. Apparent viscosity as a function of copolymer concentrations for HGP, GP-T, HP-T, and HPAM at shear rate of $170 \mathrm{~s}^{-1}$ at $25^{\circ} \mathrm{C}$.

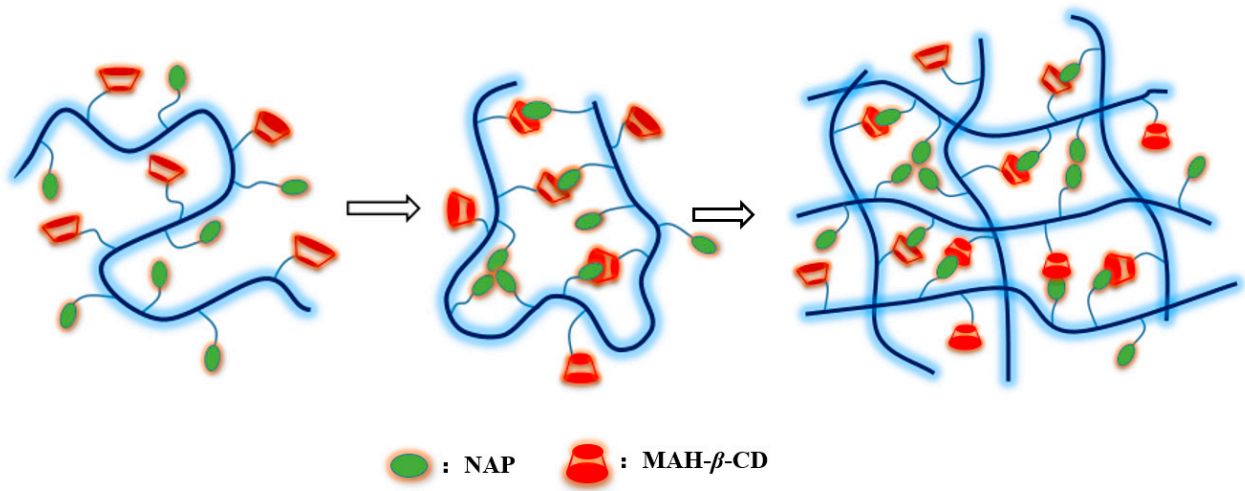

Figure 8. The thickening mechanism of HGP.

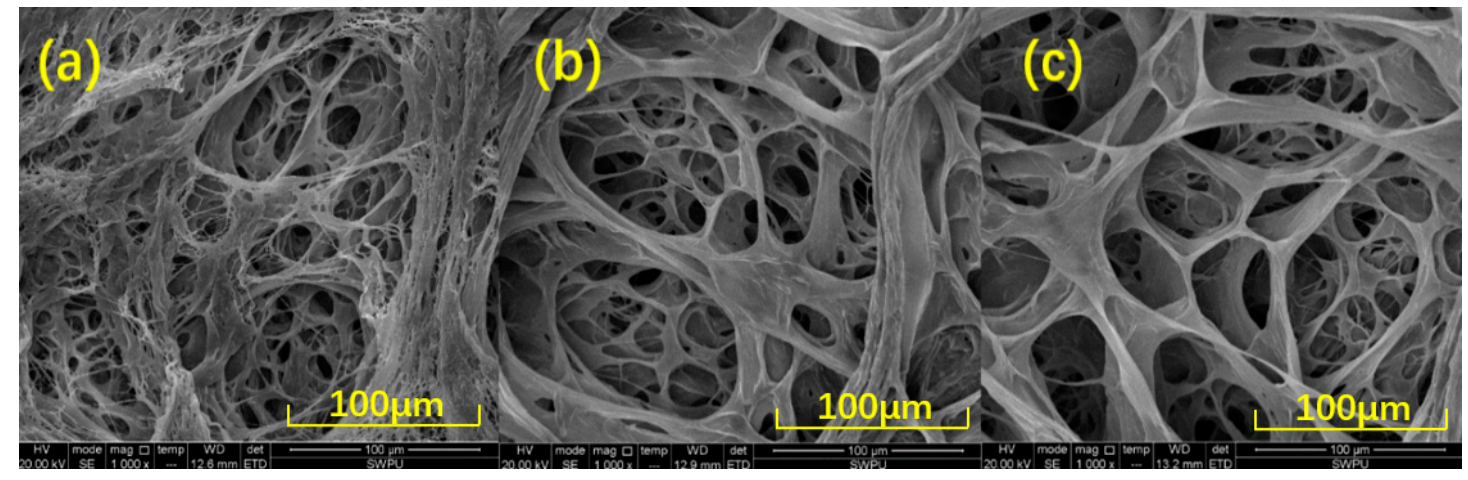

Figure 9. SEM morphologies of 0.6 wt.\% GP-T, HP-T, and HGP in DI water (1000×). (a) HGP, (b) HP-T, (c). GP-T.

\subsection{Viscoelasticity}

The change in storage modulus $\left(G^{\prime}\right)$, loss modulus $\left(G^{\prime \prime}\right)$, and intersection $\left(G_{c}\right)$ depended on the frequency [4]. Figure 10 shows that for HGP, HP-T, and GP-T, at a low frequency where the $G^{\prime}$ was less than $G^{\prime \prime}$, the viscous modulus played a dominant role. The storage and loss moduli increased with the increase in frequency. As the scanning frequency further increased above the characteristic frequency where $G^{\prime}$ and $G^{\prime \prime}$ crossed each other $\left(G_{c}\right)$, the $G^{\prime}$ was more significant than the $G^{\prime \prime}$, indicating that the $G^{\prime}$ played a 
dominant role. The relaxation time $t_{c}$ corresponding to the intersection $G_{c}$ can be used to describe the solution viscoelasticity. A longer $t_{c}$ verifies that the solution contributes more to elastic efficiency. Table 1 shows the relaxation times of different solutions according to the calculation results; the $t_{c}$ of HGP, GP-T, and HP-T are about 2.68, 0.451 , and $1.3103 \mathrm{~s}$, respectively, suggesting that the host-guest structure can endow the polymer solution with superior viscoelasticity.
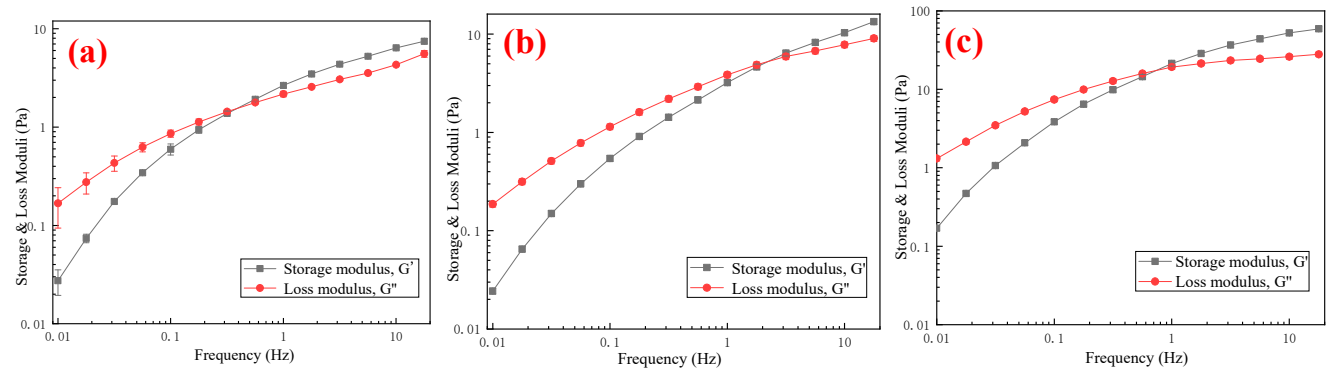

Figure 10. $G^{\prime}$ and $G^{\prime \prime}$ varying as a function of angular frequency for three polymers. (a) HGP, (b) GP-T, (c) HP-T.

Table 1. Crossover frequencies and longest relaxation times of three polymer solutions.

\begin{tabular}{lccc}
\hline & \multicolumn{3}{c}{ Polymer } \\
\hline & HGP & GP-T & HP-T \\
\hline Crossover frequency (Hz) & 0.372 & 2.20 & 0.767 \\
Relaxation time (s) & 2.688 & 0.451 & 1.303 \\
\hline
\end{tabular}

\subsection{Shear Tolerance}

As shown in Figure 11, the viscosity decreased as the shear rate increased, indicating that those polymer solutions are typical pseudoplastic fluids. With the increase in shear rate, the forces between groups and molecular chains were destroyed, including hydrogen bonds, van der Waals forces, and hydrophobic associations. The flow resistance of the system dropped dramatically, resulting in a decrease in apparent viscosity. In addition, the viscosities of HGP, GP-T, and HP-T were $87.8 \mathrm{mPa} \cdot \mathrm{s}, 47.5 \mathrm{mPa} \cdot \mathrm{s}$, and $53.2 \mathrm{mPa} \cdot \mathrm{s}$, respectively, at a shear rate of $1000 \mathrm{~s}^{-1}$. A similar situation can also be observed in Figure 12. When the shear rate alternated between $170 \mathrm{~s}^{-1}$ and $510 \mathrm{~s}^{-1}$, the HGP solution showed the best shear recovery performance, indicating that the HGP solution had good shear resistance properties caused by the interaction between the $\beta-C D$ and the hydrophobic group. When the shear occurred, the host-guest interaction was destroyed, producing many free host and guest groups at the cross-section. While shear rate decreased, the host-guest effect reformed, leading to the recovery in the viscosity of polymer solutions.

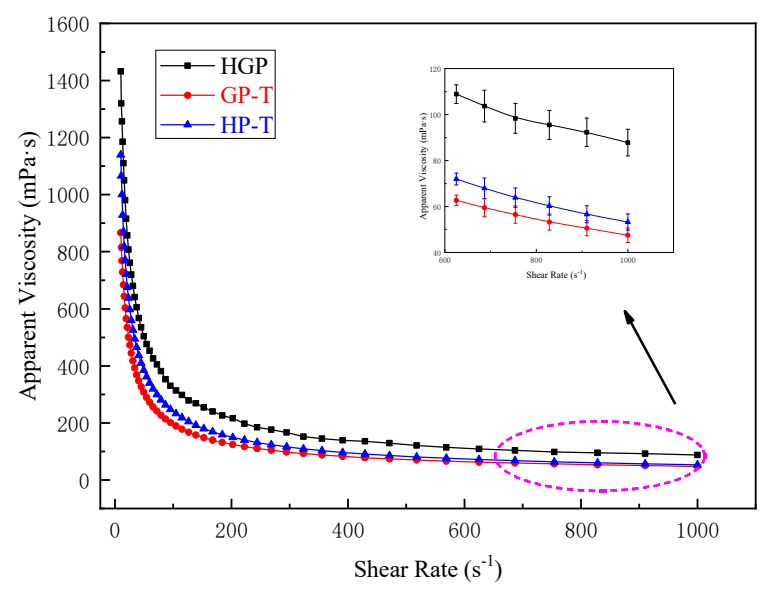

Figure 11. Apparent viscosity relative to shear rate of the HGP, GP-T, and HP-T at $0.6 \mathrm{wt} . \%$. 


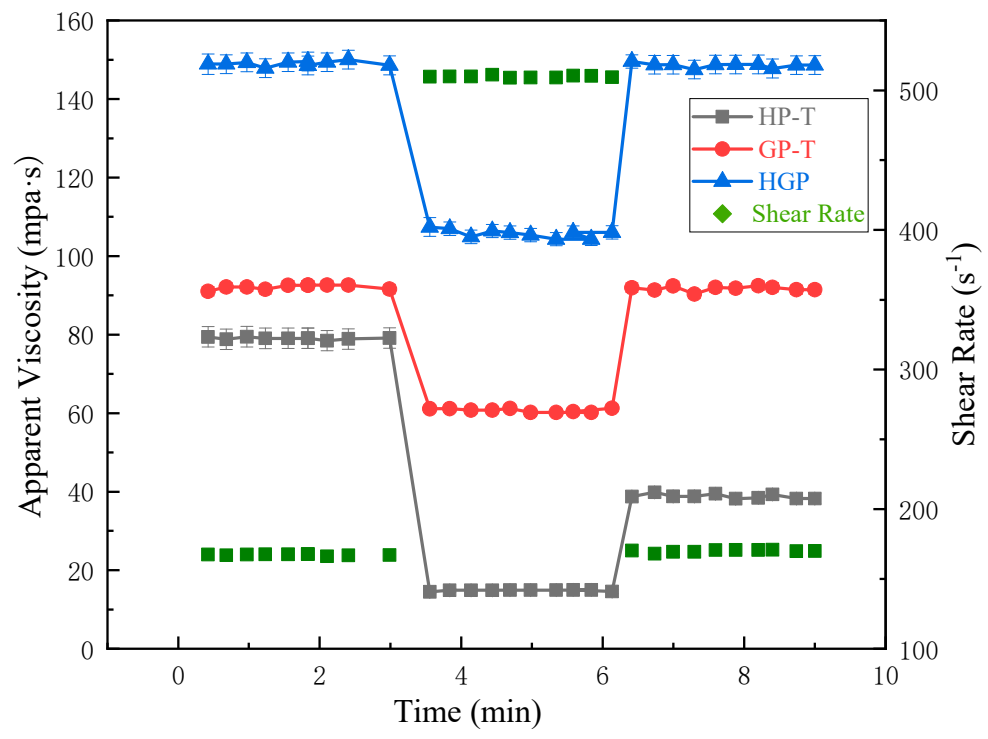

Figure 12. The HGP, GP-T, and HP-T apparent viscosity relative to alternating shear rate.

The polymer will experience shear and temperature increase in the reservoir. Thus, it is necessary to evaluate the behaviors of polymers in formation water. In the experiment, formation water of the SZ1-1 oilfield in the Bohai Sea was used to prepare $0.6 \mathrm{wt} . \%$ polymer solution at $25^{\circ} \mathrm{C}$; the formation water composition is shown in Table 2 .

Table 2. Formation water ion composition.

\begin{tabular}{cccccccc}
\hline Composition & $\mathrm{Na}^{+} / \mathrm{K}^{+}$ & $\mathrm{Ca}^{2+}$ & $\mathbf{M g}^{2+}$ & $\mathbf{C O}_{3}{ }^{2-}$ & $\mathbf{H C O}_{3}{ }^{-}$ & $\mathbf{S O}_{4}{ }^{2-}$ & $\mathrm{Cl}^{-}$ \\
\hline Content $\left(\mathrm{mg} \cdot \mathrm{L}^{-1}\right)$ & 3091.64 & 276.17 & 158.68 & 14.21 & 311.48 & 85.29 & 5436.34 \\
\hline
\end{tabular}

Figure 13 shows that the viscosity of the polymer solution decreased as the temperature increased. From $30{ }^{\circ} \mathrm{C}$ to $120^{\circ} \mathrm{C}$, the HGP viscosity maintains at approximately $90 \mathrm{mPa} \cdot \mathrm{s}$, significantly greater than HP-T (51 mPa $\cdot \mathrm{s})$ and GP-T $(30 \mathrm{mPa} \cdot \mathrm{s})$, indicating that the HGP has greater temperature resistance than HP-T and GP-T. $\beta$-CD encapsulating the hydrophobic chain was an exothermic reaction [24,31], leading to the dissociation of the $\beta$-CD inclusion complex with increasing temperature due to the Brownian motion. In addition, the weakening of the hydrophobic association resulted in a considerable reduction in viscosity. However, the conformation of the polymer at high temperature determines its hydrodynamic volume, which determines the viscosity. The conformation is mainly affected by the rigidity of the polymer and the forces between groups and molecular chains. Although rigidity of the polymer worsens the flexibility of the molecular chain, it can make the molecular chain more extended [32]. Therefore, increasing the rigidity of the polymer can effectively increase the temperature resistance, and the introduction of the hydrophobic group can also change the conformation of the polymer at high temperatures [33]. Thus, the temperature resistance of the polymer solutions at high temperatures was HGP > GP-T > HP-T.

\subsection{Salt Tolerance}

Inorganic salt has a negative influence on the polymer solution viscosity, especially the divalent ones, such as $\mathrm{Ca}^{2+}$ and $\mathrm{Mg}^{2+}$ [34]. As shown in Figure 14a, the viscosity change of the HGP solution was more pronounced than those of the HP-T and GP-T solutions. When the $\mathrm{NaCl}$ concentration was less than $20,000 \mathrm{mg} / \mathrm{L}$, the viscosity of the HGP solution decreased as the $\mathrm{NaCl}$ concentration increased. This can be interpreted as sodium ions shielding the carboxylate ions on the polymer, which reduces electrostatic 
repulsion between the anions, causing the polymer backbone to curl, resulting in the reduction in viscosity at the initial stage.

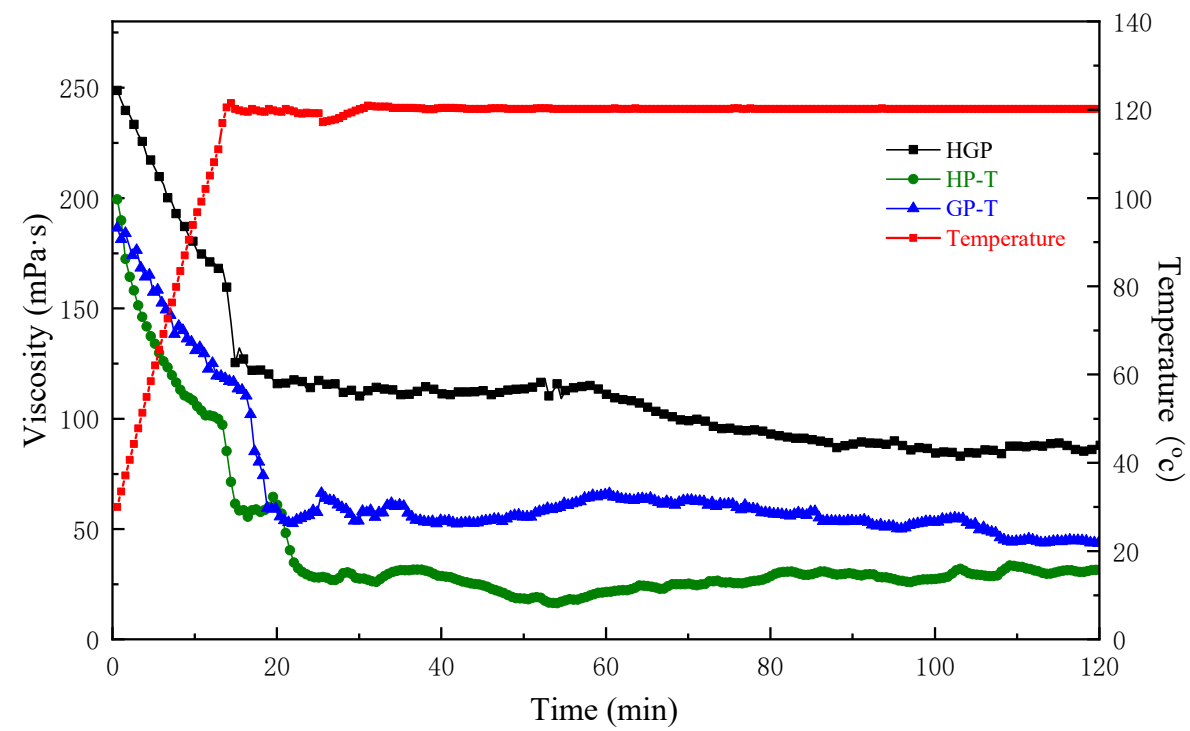

Figure 13. Rheological properties of copolymers HGP, HP-T, and GP-T at $120^{\circ} \mathrm{C}$.
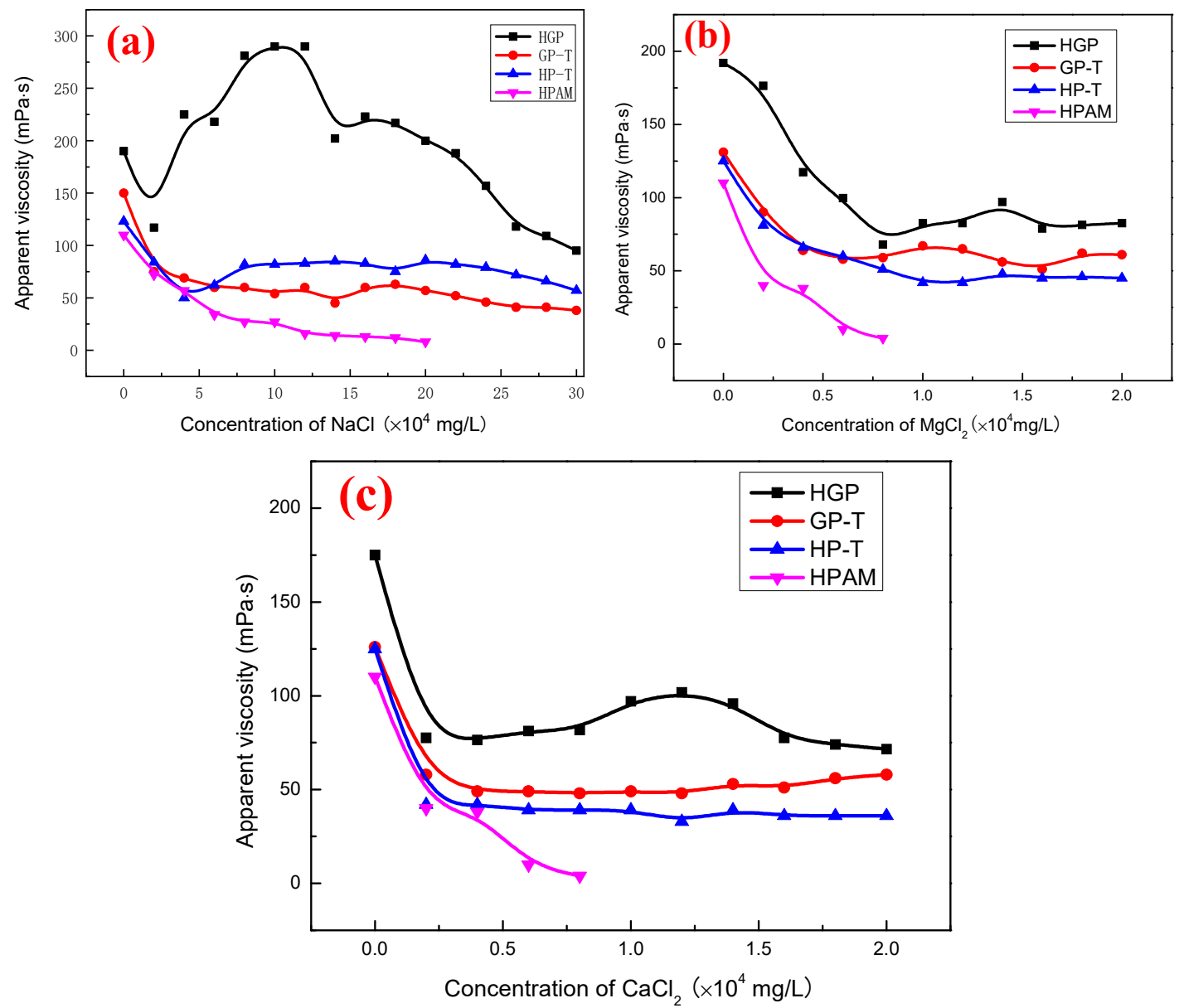

Figure 14. Effects of inorganic salt concentrations on the viscosities of HGP, GP-T, HP-T, and HPAM, 0.6 wt. \%. (a) NaCl, (b) $\mathrm{MgCl}_{2}$, (c) $\mathrm{CaCl}_{2}$. 
When the content of $\mathrm{NaCl}$ increases from $2 \times 10^{4} \mathrm{mg} / \mathrm{L}$ to $12 \times 10^{4} \mathrm{mg} / \mathrm{L}$, the polarity of the solution increases, which strengthens the hydrophobic association and the hostguest effect. Macroscopically, the viscosity of HGP increased from $117 \mathrm{mPa} \cdot \mathrm{s}$ to $290 \mathrm{mPa} \cdot \mathrm{s}$. Further, when the $\mathrm{NaCl}$ concentration reached $30 \times 10^{4} \mathrm{mg} / \mathrm{L}$, the viscosity lowered from $290 \mathrm{mPa} \cdot \mathrm{s}$ to $89 \mathrm{mPa} \cdot \mathrm{s}$. This can be clarified as when the salt concentration further increases, the electrostatic shielding effect was greater than the host-guest interaction and hydrophobic association, resulting in the polymer backbone crimp and a sharp decrease in viscosity. For HPAM, the electrostatic shielding effect of salt on carboxylate ions was significant, and the polymer backbone crimped seriously, so the viscosity of HPAM is almost the same as that of water [35].

Similarly, the effect of $\mathrm{CaCl}_{2}$ and $\mathrm{MgCl}_{2}$ on the viscosity of the polymer solution was also investigated, as shown in Figure 14b,c. With the increase in concentrations of $\mathrm{CaCl}_{2}$ and $\mathrm{MgCl}_{2}$, the viscosity of the HGP was higher than that of HP-T and GP-T, indicating that the host-guest effect between NAP and $\beta$-CD can improve the salt tolerance of the polymer. When the brine concentration reached $2 \times 10^{4} \mathrm{mg} / \mathrm{L}$, the viscosity of $\mathrm{HGP}$ in $\mathrm{CaCl}_{2}$ and $\mathrm{MgCl}_{2}$ decreased from the initial viscosity to 71.6 and 82.5 , respectively. However, when the concentration of inorganic salts reached $7000 \mathrm{mg} / \mathrm{L}$, the viscosity of the HPAM solution was reduced almost to zero.

\section{Conclusions}

In this study, a water-soluble polymer, HGP, was synthesized that combined the hostguest effect of $\beta$-cyclodextrin and NAP. From the experiments, six conclusions were drawn:

(1) HGP with good properties was synthesized by free-radical polymerization. NAP, MAH- $\beta-C D$, and HGP were characterized by ${ }^{1} \mathrm{H}$ NMR spectroscopy.

(2) HGP using the host-guest strategy encompasses a better solubility than HAWSPs.

(3) The highest effectiveness of host-guest structures can be formed in an aqueous solution when the molar ratio of $\beta$-CD to NAP is 1:1.

(4) When the concentration increased from $1000 \mathrm{mg} / \mathrm{L}$ to $3500 \mathrm{mg} / \mathrm{L}$, the growth rate in viscosity of the HGP was $168 \%$. The microscopic reason was that microcosmic network structures in HGP are much denser than those of GP-T and HP-T.

(5) The host-guest effect between NAP and MAH- $\beta$-CD groups improves the performance of HGP, including the shear, viscoelasticity, and salt tolerance.

(6) For the polymer solutions prepared by the formation water of the SZ1-1 oilfield in the Bohai Sea, HGP maintains the viscosity of $90 \mathrm{mPa} \cdot \mathrm{s}$ at $120^{\circ} \mathrm{C}, 170 \mathrm{~s}^{-1}$, which was higher than HP-T and GP-T.

Therefore, HGP has good application prospects for drilling, hydraulic fracturing, and enhanced oil recovery.

Author Contributions: Formal analysis, T.X. and Y.Z.; Funding acquisition, X.Y. and C.L.; Investigation, A.D., Q.Z. and J.M. (Jinhua Mao); Software, H.Z.; Writing—original draft, T.X.; Writing—review and editing, T.X. and J.M. (Jincheng Mao). All authors have read and agreed to the published version of the manuscript.

Funding: This research was funded by National High Technology Research \& Development Program (Grant Nos. 2016ZX05053, 2016ZX05014-005-007), China Postdoctoral Science Foundation (Grant Nos. 2019M650250), and the National Natural Science Foundation of China.

Institutional Review Board Statement: Not applicable.

Informed Consent Statement: Not applicable.

Data Availability Statement: The data presented in this study are available on request from the corresponding author.

Acknowledgments: The research is partly supported by the National High Technology Research \& Development Program (2016ZX05053, 2016ZX05014-005-007), China Postdoctoral Science Foundation 
(2019M650250), and the National Natural Science Foundation of China (41902303). We thank Jincheng Mao, Xiaojiang Yang, and Chong Lin for providing the helpful of Funding.

Conflicts of Interest: The authors declare no conflict of interest.

\section{References}

1. Wever, D.A.Z.; Picchioni, F; Broekhuis, A. Polymers for enhanced oil recovery: A paradigm for structure-property relationship in aqueous solution. Prog. Polym. Sci. 2011, 36, 1558-1628. [CrossRef]

2. Kulawardana, E.U.; Koh, H.; Kim, D.H.; Liyanage, P.J.; Upamali, K.A.; Huh, C.; Weerasooriya, U.; Pope, G.A. Rheology and Transport of Improved EOR Polymers under Harsh Reservoir Conditions. SPE Improv. Oil Recovery Symp. 2012. [CrossRef]

3. Bock, J.; Valint, P.L.; Pace, S.J. Enhanced Oil Recovery with Hydrophobically Associating Polymers Containing Sulfonate Functionality. U.S. Patent US4702319 A, 27 October 1987.

4. Zhang, Y.; Mao, J.; Zhao, J.; Yang, X.; Xu, T.; Lin, C.; Mao, J.; Tan, H.; Zhang, Z.; Yang, B.; et al. Preparation of a HydrophobicAssociating Polymer with Ultra-High Salt Resistance Using Synergistic Effect. Polymers 2019, 11, 626. [CrossRef] [PubMed]

5. Nasr-El-Din, T. Water-soluble hydrophobically associating polymers for improved oil recovery: A literature review. J. Pet. Sci. Eng. 1998, 19, 265-280.

6. Zhao, T.; Xing, J.; Dong, Z.; Tang, Y.; Pu, W. Synthesis of Polyacrylamide with Superb Salt-Thickening Performance. Ind. Eng. Chem. Res. 2015, 54, 151019101705006. [CrossRef]

7. Yu, W.; Feng, Y.; Wang, B.; Lu, Z. A novel thermoviscosifying water-soluble polymer: Synthesis and aqueous solution properties J. Appl. Polym. Sci. 2010, 116, 3516-3524.

8. Zou, C.; Gu, T.; Xiao, P.; Ge, T.; Wang, M.; Wang, K. Experimental Study of Cucurbit[7]uril Derivatives Modified Acrylamide Polymer for Enhanced Oil Recovery. Ind. Eng. Chem. Res. 2014, 53, 7570-7578. [CrossRef]

9. Abdel-Alim, A.H.; Hamielec, A.E. Hamielec, Shear degradation of water-soluble polymers. I. Degradation of polyacrylamide in a high: Hear couette viscometer. J. Appl. Polym. Sci. 1973, 17, 3769-3778. [CrossRef]

10. Basedow, A.M.; Ebert, K.H. Effects of mechanical stress on the reactivity of polymers: Activation of acid hydrolysis of dextran by ultrasound. Polym. Bull. 1979, 1, 299-306. [CrossRef]

11. Osman, S.K.; Brandl, F.P.; Zayed, G.M.; Teßmar, J.K.; Göpferich, A.M. Cyclodextrin based hydrogels: Inclusion complex formation and micellization of adamantane and cholesterol grafted polymers. Polymer 2011, 52, 4806-4812. [CrossRef]

12. Wenz and Gerhard, Cyclodextrin Inclusion Polymers Forming Hydrogels. Adv. Polym. Sci. 2009, 222, 175-203.

13. Topuz, F.; Holtzl, T.; Szekely, G. Scavenging organic micropollutants from water with nanofibrous hypercrosslinked cyclodextrin membranes derived from green resources. Chem. Eng. J. 2021, 419, 129443. [CrossRef]

14. Cecone, C.; Hoti, G.; Krabicová, I.; Appleton, S.L.; Caldera, F.; Bracco, P.; Zanetti, M.; Trotta, F. Sustainable synthesis of cyclodextrin-based polymers by exploiting natural deep eutectic solvents. Green Chem. 2020, 22, 5806-5814. [CrossRef]

15. Chen, X.; Liu, J.; Yan, J.-L.; Fang, Y. Host-Guest Interactions between N,N'-Bis(ferrocenylmethylene)-Diaminobutane and Benzenetetracarboxylic Dianhydride Bridged Bis( $\beta$-cyclodextrin)s. Chin. J. Chem. 2006, 24, 1687-1691. [CrossRef]

16. Jing, L.; Yan, J.; Chen, X.; Fang, Y. Studies on the conformational behavior of acenaphthylene-labeled poly(acrylamide- co -acryloyl-6-deoxy-6-amino- $\beta$-cyclodextrin). Colloid Polym. Sci. 2007, 285, 881-889.

17. Li, S.; Zhang, X.; Liang, H.; Wang, X. Supramolecular Hydrogels Obtained by Host-Guest Interactions of Cyclodextrin Dimers with Adamantyl-Containing LCST Copolymers. Acta Chim. Sin. 2012, 70, 1013-1020. [CrossRef]

18. Huh, K.M.; Cho, Y.W.; Chung, H.; Kwon, I.C.; Jeong, S.Y.; Ooya, T.; Lee, W.K.; Sasaki, S.; Yui, N. Supramolecular hydrogel formation based on inclusion complexation between poly(ethylene glycol)-modified chitosan and alpha-cyclodextrin. Macromol. Biosci. 2004, 4, 92. [CrossRef] [PubMed]

19. Liu, Y.Y.; Fan, X.; Sun, L. Synthesis and properties of poly(n-isopropylacrylamide)/ $\beta$-cyclodext rin ionic polymer. Acta Polym. Sin. 2005, 1, 471-475.

20. Wang, J.; Jiang, M. Studies on self-assembly from lightly-crosslinked polymers via inclusion interaction. Acta Polym. Sin. 2007, 7, 979-985. [CrossRef]

21. Weickenmeier, M.; Wenz, G.; Huff, J. Association thickener by host guest interaction of a $\beta$-cyclodextrin polymer and a polymer with hydrophobic side-groups. Macromol. Rapid Commun. 1997, 18, 1117-1123. [CrossRef]

22. Charlot, A.; Auzely-Velty, R.; Rinaudo, M. Specific interactions in model charged polysaccharide systems. J. Phys. Chem. B 2008, 107, 8248-8254. [CrossRef]

23. Pu, W.-F.; Yang, Y.; Wei, B.; Yuan, C. The Potential of a $\beta$-Cyclodextrin/Adamantane Modified Copolymer in Enhancing Oil Recovery through Host-Guest Interactions. Ind. Eng. Chem. Res. 2016, 55, 8679-8689. [CrossRef]

24. Zou, C.; Liao, W.; Zhang, L.; Chen, H. Study on acidizing effect of $\beta$-cyclodextrin-PBTCA inclusion compound with sandstone. J. Pet. Sci. Eng. 2011, 77, 219-225. [CrossRef]

25. Liu, X.; Jiang, W.; Gou, S.; Ye, Z.; Feng, M.; Lai, N.; Liang, L. Synthesis and evaluation of novel water-soluble copolymers based on acrylamide and modular $\beta$-cyclodextrin. Carbohydr. Polym. 2013, 96, 47-56. [CrossRef]

26. Zou, C.; Zhao, P.; Hu, X.; Yan, X.; Zhang, Y.; Wang, X.; Song, R.; Luo, P. $\beta$-Cyclodextrin-Functionalized Hydrophobically Associating Acrylamide Copolymer for Enhanced Oil Recovery. Energy Fuels 2013, 27, 2827-2834. [CrossRef]

27. Huang, G.L.; Zhang, Y.; Ren, F.; Zheng, F.L. Study on the difference of envelope between 1-bromonaphthalene, 2bromonaphthalene and $\beta$-cyclodextrin. J. Jimei Univ. (Nat. Ed.) 2003, 1, 22-27. 
28. He, Y.; Xu, Z.H.; Wu, F.; Qing, D. Synthesis and evaluation of a novel amphiphilic polymer containing $\beta$-cyclodextrin. Polym. Sci. 2014, 56, 822-829. [CrossRef]

29. Yan, J.; Du, L.; Lu, F.; Li, Z.; Yang, J.; Bie, S.; Zhang, J. Synthesis and properties of functionalized $\beta$-cyclodextrin copolymer and its metal complexes. Polym. Bull. 2006, 57, 481-489.

30. Candau, F.; Regalado, E.J.; Selb, J. Recent advances in associating polymers prepared by micellar polymerization. Macromol. Symp. 2000, 150, 241-249. [CrossRef]

31. Shan, J.; Li, J.N.; Jiang, Z.T. Inclusion reactions of $\beta$-cyclodextrin and its derivatives with cinnamaldehyde in Cinnamomum loureirii essential oil. Eur. Food Res. Technol. 2010, 230, 543-550.

32. Yang, B.; Mao, J.; Zhao, J.; Shao, Y.; Zhang, Y.; Zhang, Z.; Lu, Q. Improving the Thermal Stability of Hydrophobic Associative Polymer Aqueous Solution Using a "Triple-Protection" Strategy. Polymers 2019, 11, 949. [CrossRef] [PubMed]

33. Zhang, Y.; Mao, J.; Zhao, J.; Yang, X.; Zhang, Z.; Yang, B.; Zhang, W.; Zhang, H. Preparation of a Novel Ultra-High Temperature Low-Damage Fracturing Fluid System Using Dynamic Crosslinking Strategy. Chem. Eng. J. 2018, 354, 913-921. [CrossRef]

34. Tian, J.; Mao, J.; Zhang, W.; Yang, X.; Lin, C.; Cun, M.; Mao, J.; Zhao, J. Application of a Zwitterionic Hydrophobic Associating Polymer with High Salt and Heat Tolerance in Brine-Based Fracturing Fluid. Polymers 2019, 11, 2005. [CrossRef] [PubMed]

35. Wang, W.; Yang, H.; Yan, Y.; Wang, M. Study on characterization of heat-resistant and salt-tolerant polymer pama and properties of its salting solution. Pet. Process. Petrochem. 2014, 45, 31-34. 